\title{
Thermal modeling and characterization for designing reliable power converters for LHC power supplies
}

\author{
Massimo Lazzaroni $^{1,2}$, Mauro Citterio ${ }^{2}$, Stefano Latorre ${ }^{2}$, Agostino Lanza ${ }^{3}$, Paolo Cova ${ }^{4,3}$, Nicola \\ Delmonte $^{4,3}$, Francesco Giuliani ${ }^{4}$ \\ ${ }^{1}$ Dipartimento di Fisica, Università degli Studi di Milano, via Celoria, 16, 20133 Milano, Italy \\ 2 INFN Milano, via G. Celoria, 16, 20133 Milano, Italy \\ ${ }^{3}$ INFN Pavia, via A. Bassi, 6, 27100 Pavia, Italy \\ ${ }^{4}$ Dipartimento di Ingegneria dell'Informazione, University of Parma, viale G.P. Usberti 181/A, 43124 Parma, Italy
}

\begin{abstract}
Power supplies for LHC experiments (ATLAS) require DC-DC power converters able to work in very hostile environments. The APOLLO collaboration, funded by the Italian Istituto Nazionale di Fisica Nucleare (INFN), aims to study dedicated topologies and to design, build and test demonstrators, developing the needed technology for the industrialization phase.

Besides the presence of radiation and magnetic fields, thermal specifications are particularly stringent in the working environment. In order to have the wanted features in terms of reliability and availability during the experimental activity, these power electronics circuits must be cooled by specifically designed water heat sinks, and an accurate thermal design is mandatory in order to guarantee safe and reliable operation. Moreover, an optimized thermal design allows to have a maintenance strategy in compliance with the requirements of the experiments.

In this paper thermal characterization is used for tuning a coupled thermo-fluid-dynamic 3D numerical model, for both the water heat sink and the whole system. Based on this model an optimized water heat sink was designed and fabricated. Thermal characterization of the power converter demonstrator in different operating conditions shows good agreement with simulation results.
\end{abstract}

\section{Section: RESEARCH PAPER}

Keywords: Measurement; Reliability; RAMS; Hostile environment; LHC; ATLAS

Citation: Massimo Lazzaroni, Mauro Citterio, Stefano Latorre, Agostino Lanza, Paolo Cova, Nicola Delmonte, Francesco Giuliani, Thermal modeling and characterization for designing reliable power converters for LHC power supplies, Acta IMEKO, vol. 3, no. 4, article 5, December 2014, identifier: IMEKO-ACTA03 (2014)-04-05

Editor: Paolo Carbone, University of Perugia

Received October $11^{\text {th }}, 2013$; In final form October $11^{\text {th }}, 2013$; Published December 2014

Copyright: (C) 2014 IMEKO. This is an open-access article distributed under the terms of the Creative Commons Attribution 3.0 License, which permits unrestricted use, distribution, and reproduction in any medium, provided the original author and source are credited

Funding: This work was supported by Apollo Collaboration of INFN, Italy

Corresponding author: Massimo Lazzaroni, e-mail: massimo.lazzaroni@unimi.it

\section{INTRODUCTION}

The Large Hadron Collider (LHC) is, nowadays, the world's largest and highest-energy particle operative accelerator, built by the European Organization for Nuclear Research (CERN). Founded in 1954, the CERN laboratory sits astride the Franco-Swiss border near Geneva [1]. The LHC can be used in order to verify the predictions of different theories of particle physics and high-energy physics with particular attention to prove the existence of the Higgs boson but also the large family of new particles predicted by super-symmetric theories. The aforementioned collider extends the frontiers of particle physics thanks to its high energy and luminosity [2]. It is important to underline that inside the collider high interaction rates, radiation doses, particle multiplicities and energies are present. All this pushes the features of the used electronic instrumentations and measurements equipment at new standards that are necessary to consider during the design phase. This is particularly true for the detector ATLAS (A Toroidal LHC ApparatuS) and for every device involved in the experiments [1], [2]. In fact, electronic converters employed in power supplies for the LHC ATLAS experiments operate in a hostile environment, due to the simultaneous presence of radiation and high static magnetic field, which impose severe design constraints. Moreover, 


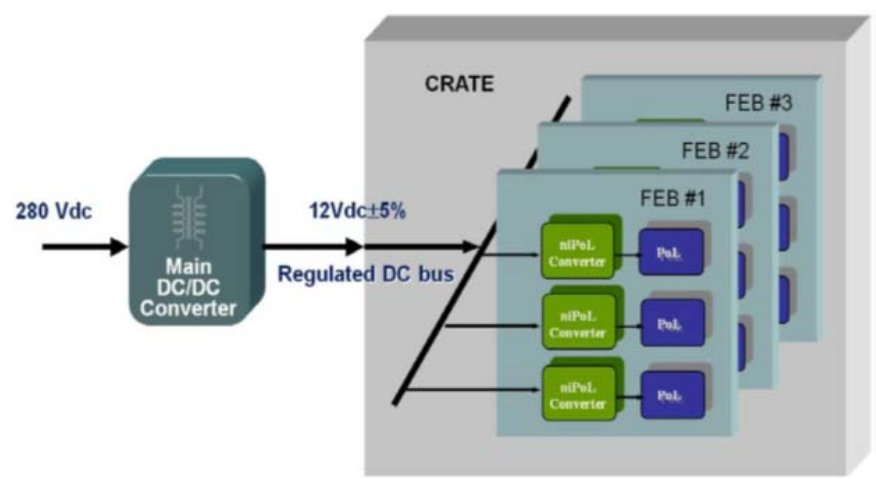

Figure 1. The proposed power supply distribution for ATLAS LAr calorimeter [10].

the power supply has to be quasi-adiabatic, due to the proximity of very sensitive detection circuitry, and this requirement implies water cooling and very stringent thermal constraints [3], [4]. Thermal management represents the key issue in designing these converters and accurate thermal modelling is mandatory to maximize the RAMS performances (Reliability, Availability, Maintainability and Safety) [5], [6].

In the present work accurate thermal modelling of the water heat sink is addressed, in order to design an optimized water path for a specific converter which will be possibly adopted in the next ATLAS power supplies.

The Phase-2 upgrade of the LHC is planned on 2022 long shutdown. The detectors will be upgraded or substituted, and new ones will be installed to improve the performances and sustain the higher rates and backgrounds at the new design luminosity: $5 \times 10^{34} \mathrm{~cm}^{-2} \mathrm{~s}^{-1}$. This increase of radiation background will cause the accumulation of a Total Ionizing Dose (TID) up to $10 \mathrm{kGy}$ in Silicon, and fluences up to $2 \times 10^{13}$ protons $/ \mathrm{cm}^{2}$ and $8 \times 10^{13}$ neutrons $/ \mathrm{cm}^{2}$. Both the new scenario and the increased power demand of the detectors, lead to re-design the power distribution system.

A description of the developed $1.5 \mathrm{~kW}$ DC-DC

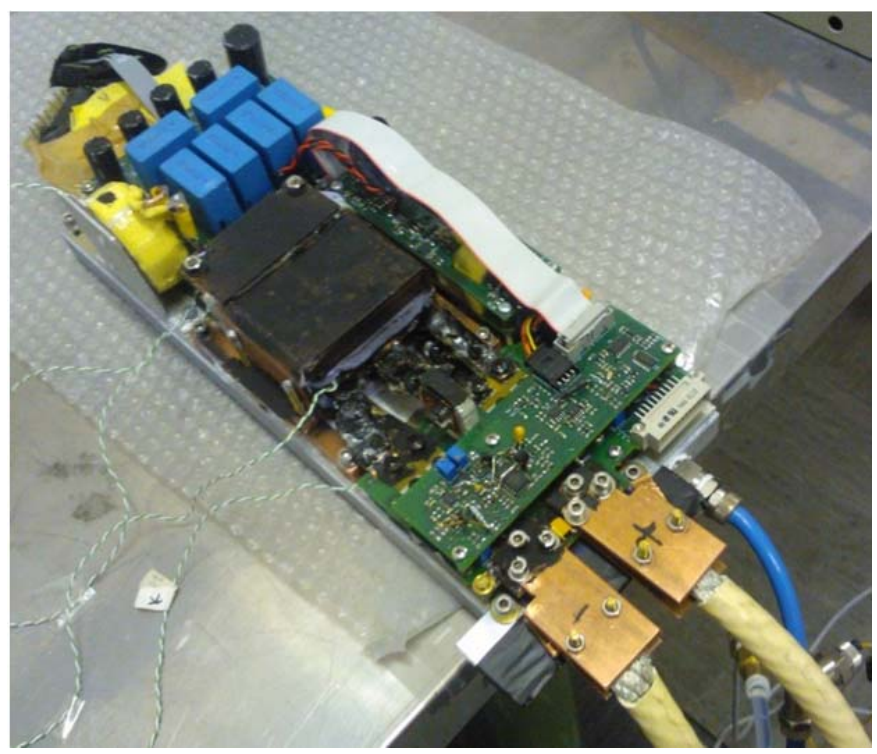

Figure 2. The implemented Main Converter. converter can be found in [7] and a detailed thermal model of it, with identification of the main heating component is reported in [8]. The proposed power distribution system (Figure 1) and the implemented Main Converter (MC) (Figure 2), will be briefly described in Section 2 whereas in Section 3 a theory of reliability will be given. For further details see [7].

For ad-hoc water heat sink development, a fluid-dynamic model of the water path has to be coupled with thermal models of both liquid and solid domains of the heat sink. This is not an obvious task, since some parameters are known with large uncertainty and the models have to be tuned experimentally. These aspects will be discussed in Section 4 in which the procedure followed for setting and tuning such models on the basis of thermal characterization of a known heat sink prototype will be described. Moreover the thermal behaviour of the whole converter mounted on the heat sink has to be simulated. Due to the complexity of the converter structure, which is made by many heating components, an established simplifying procedure has been followed to obtain an effective reduced converter thermal model [9].

On the basis of the numerical thermo-fluid-dynamic model the specific water heat sink was designed and manufactured, as described in Section 5. Section 6 shows the good agreement between thermal characterization of the whole system and simulation results. Discussions concerning simulation results and the results obtained by means of a deep measurement activities will be given in Section 7. Finally, conclusions are given in Section 8.

\section{THE POWER DISTRIBUTION AND THE MAIN CONVERTER}

An isolated DC-DC MC has to supply an intermediate medium voltage bus able to distribute the voltage to the electronics installed on the detectors. At the board level, Point of Load (PoL) converters should be implemented on Front-end Boards (FEBs) for precise voltage adaptation and regulation as depicted in Figure 1 [10].

The MC is designed starting by a modular approach in order to improve the overall reliability of the system and provide the requested redundancy as well described in the following Section III. The transient-resonant topology

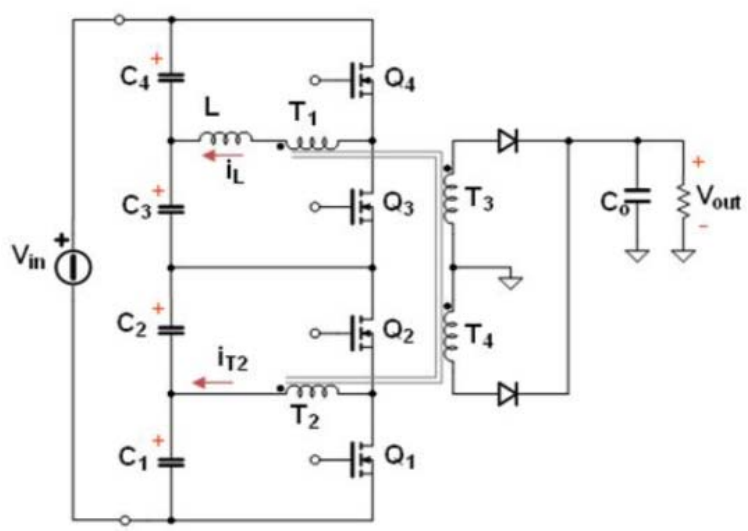

Figure 3. The adopted switch-in-line topology. 


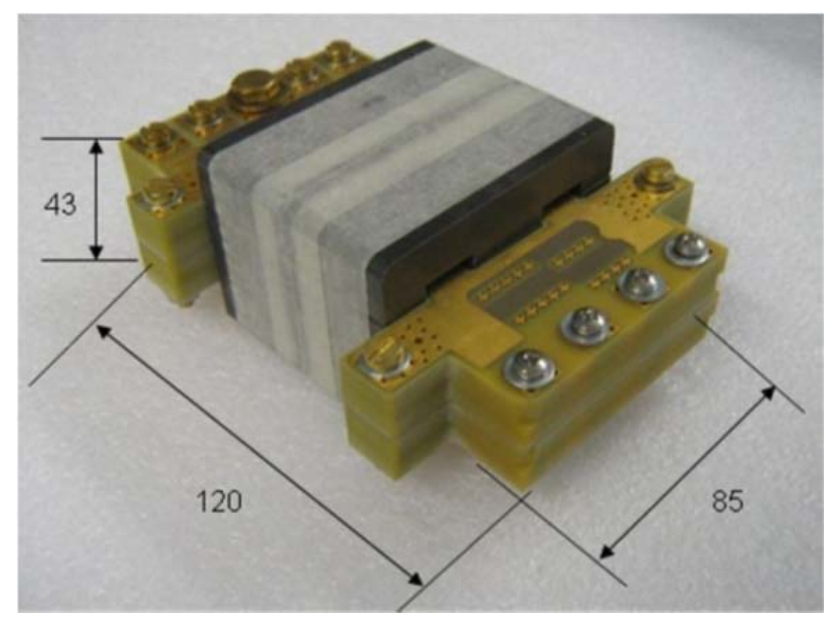

Figure 4. The proposed planar transformer [7]. Dimensions in $\mathrm{mm}$.

adopted is based upon a Switch-In-Line-Converter (SILC) and the basic schematic is drawn in Figure 3. The typical features for this topology can be summarized as: possible multiple outputs, low switch voltage stress, soft switching operation, first order dynamic, decreasing the sensitivity of power devices to ionizing radiations, limiting the overall power losses and, finally, the generated ElectroMagnetic Interference (EMI) in compliance with LHC requirements [7].

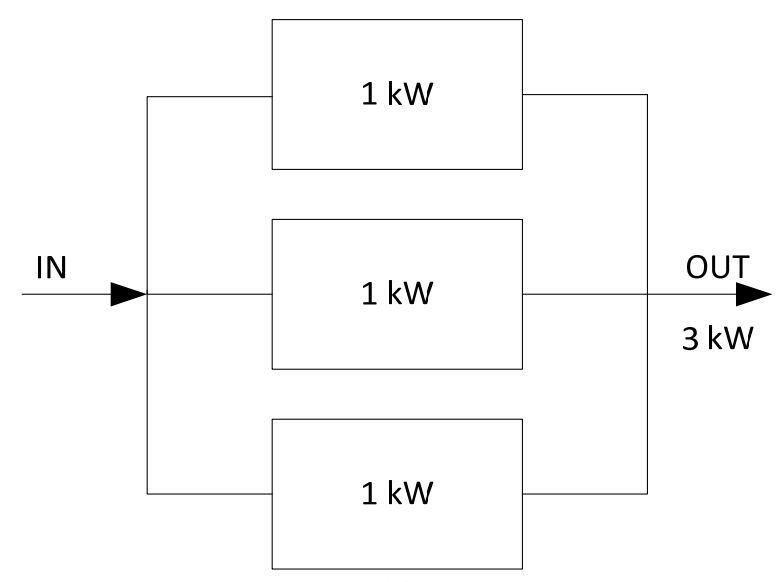

(a)

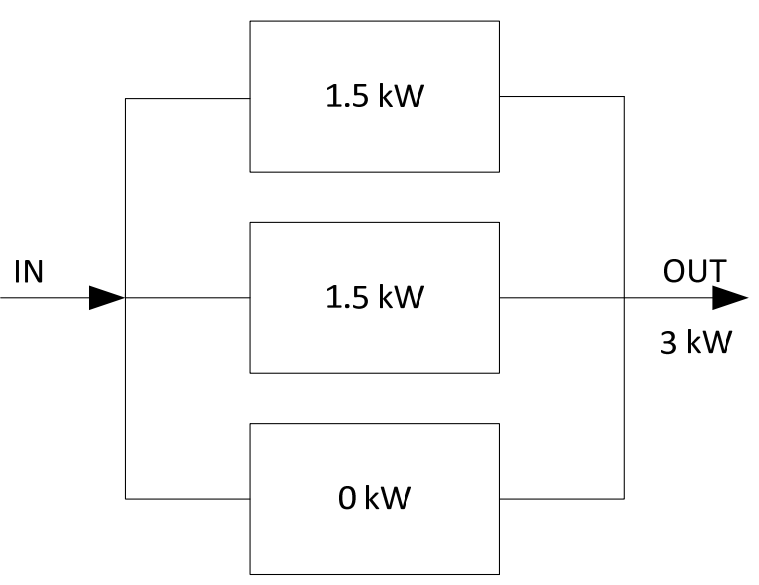

(b)

Figure 5. The functional configuration 2003 when: modules without failures (a), and with a module in fault state (b).
As far as the galvanic isolation is concerned it is guaranteed by a dedicated planar transformer ad hoc designed. The new planar transformer has overall reduced dimensions and minimizes the iron losses. The use of both non-commercial magnetic material for the transformer core and the adoption of auxiliary windings in order to face the external magnetic field has been also investigated. In particular, cores in Kool M has been used [11]. In fact, Kool M powder cores, made with a ferrous alloy powder, have low losses at elevated temperatures. Magnetic Kool M cores are made from a $85 \%$ of iron, $9 \%$ of silicon, and $6 \%$ of aluminum alloy powder in order to obtain low losses at elevated frequencies. The typical advantages of Kool $\mathrm{M \mu}$ cores are: high saturation $(1.05 \mathrm{~T})$, lower core loss than powdered iron, moderate cost, low magnetostriction, very high Curie temperature, stable performance with temperature, variety of available shapes. The very interesting features of this material is that it is suitable to be used in the switching regulator where the most important and critical parameter of the switching regulator inductor is the ability to provide inductance, or permeability, also under DC bias. Figure 4 depicts the proposed planar transformer.

\section{AN INTRODUCTION ON RELIABILITY}

All the RAMS requirements are relevant to this case. In fact, reliability is defined as the ability of an item to perform a required function under given conditions for a given time interval, and, quantitatively, assuming that the item is capable of carrying out its required function at the beginning of a specific time interval. Reliability is the probability of failure-free performance over the specified timeframe, under specified conditions [5]. Moreover, availability is the ability to perform a required function under given conditions at a given time instant or over a given time interval, assuming that the required external resources are provided [5]. Maintainability is the ability of an item under given condition of use, to be retained in, or restored to, a state in which it can perform a required function, when maintenance is performed under given conditions and using stated procedures and resources [5]. Finally, it is important to underline that also in this kind of applications, safety (qualitatively defined as the absence of catastrophic consequences on the users and the environment in case of malfunction) is mandatory. It is very important, at this point, to highlight that for these devices maintenance must be correctly scheduled in order to be in compliance with the experimental activity: some types of maintenance can be, in fact, planned only during the shutdown periods. At this aim, the maximization of the parameters connected to the reliability, availability and safety must be taken into account. For example, some kinds of redundancies are mandatory, as described in the following. Diagnostic-on-board tools can be, obviously, very useful in these kinds of applications. In fact, only appropriate diagnostic allows addressing the problem of maintenance between two different policies. In the first policy, called corrective maintenance $(\mathrm{CM})$, the 
maintenance is performed after a system failure. In the second one, called preventive maintenance (PM), maintenance is performed before a system failure [12], [13]. In order to follow this second approach, policy diagnostic tools are necessary as aforementioned. Not least, the thermal behaviour of the system has to be kept under control, in order to prevent components degradation. An accurate thermal modelling may be very useful not only for thermal sizing, but also to identify the most critical components and find the most appropriate placement of thermal sensors for diagnostics [12]-[17].

As far as the redundancy is concerned the applied approach is based on the functional configuration $k$ out of $n$. Redundancy is particularly useful in experiments where very high dependability features are mandatory. In particular, this is true if high reliability, availability and safety of equipment are requested. Parallelism of items (devices or systems) in the Reliability Block Diagram (RBD) does not mean automatically and necessarily parallel in the hardware block diagram. In the used configuration the redundant elements are subject to a lower load (load sharing) until one of the elements fails as a functional configuration denoted as Warm Redundancy (WR). In fact, in the final configuration three $1.5 \mathrm{~kW}$ Main Converter modules work together in order to deliver a power of 3 $\mathrm{kW}$. The load is shared and each module delivers $1 \mathrm{~kW}$ during safe operations. If a module fails the remaining two

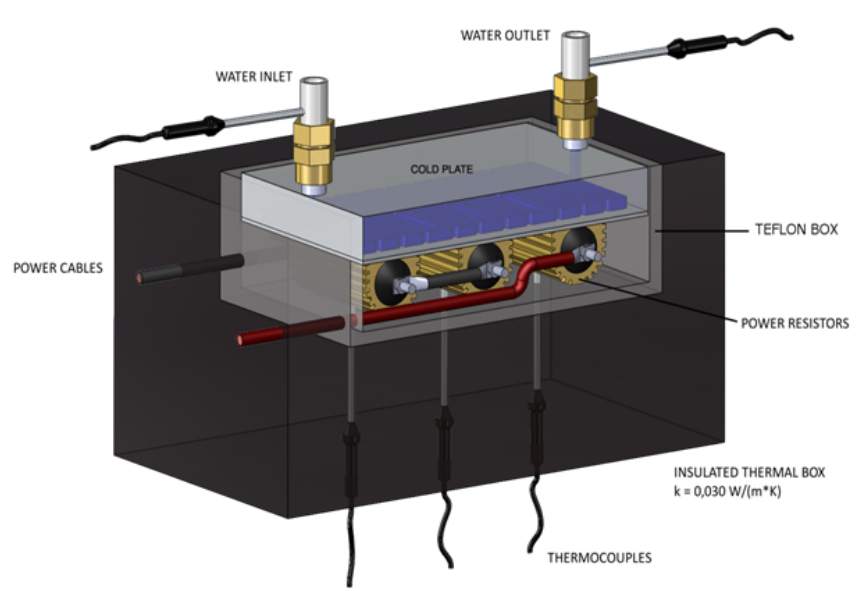

(a)

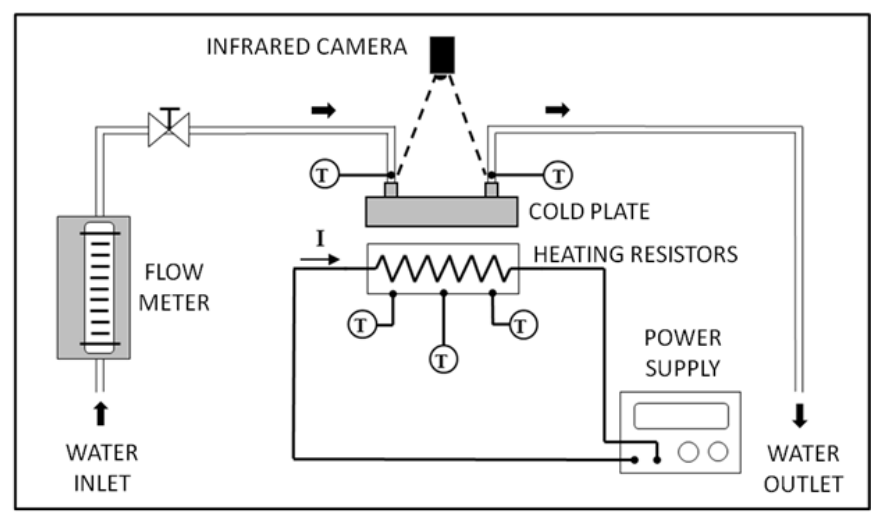

(b)

Figure 6. 3D model of experimental set-up for numerical model tuning (a) and schematic of the test bench (b). modules share the full load (in fact, each module is able to operate up to $1.5 \mathrm{~kW}$ ).

This way to operate is known as the $k$ out of $n$ functional configuration that, in the present case, results in a 2003 configuration. In this particular type of redundancy operation is ensured if at least $k$ (2) number of elements out of a total of $n$ (3) elements are functioning normally. In Figure 5 the designed situation has been drawn.

Many examples of such fault tolerant systems can be found: airplane with a multi-engine propulsion system, cockpit with a multi display system, etc.

In order to evaluate the reliability of this configuration the binomial distribution is used. Furthermore, we fix that the generic element of the system can assume only two conditions: correct functioning and failure. Indicating with $R(t)$ the reliability of the generic element and with $R_{S}(t)$ the reliability of the system, the reliability of the systems can be evaluated as [5]:

$R_{S}(t)=\sum_{i=k}^{n}\left(\begin{array}{l}n \\ i\end{array}\right)(R(t))^{i}(1-R(t))^{n-i}$

where

$\left(\begin{array}{l}n \\ i\end{array}\right)=\frac{n !}{i !(n-i) !}$.

Assuming a constant failure rate

$R_{S}(t)=\sum_{i=k}^{n}\left(\begin{array}{l}n \\ i\end{array}\right)\left(e^{-\lambda t}\right)^{i}\left(1-e^{-\lambda t}\right)^{n-i}$

the mean time to failure of the system can be immediately calculated as

$$
\operatorname{MTTF}_{S}=\int_{0}^{+\infty}\left[\sum_{i=k}^{n}\left(\begin{array}{l}
n \\
i
\end{array}\right)\left(e^{-\lambda t}\right)^{i}\left(1-e^{-\lambda t}\right)^{n-i}\right] d t .
$$

From the previous equations, it is interesting to recall that for $k=1$ this configuration coincides with the parallel configuration, while for $k=n$ with the series configuration.

\section{VALIDATION OF THERMO-FLUID-DYNAMIC FE MODEL}

A known water heat sink, made by milled aluminium, was used as a reference for thermo-fluid-dynamic 3D numerical model tuning. The thermal performances of this cooling device were characterized at various liquid flow rates and compared with simulation results in the same operating conditions.

\subsection{Experimental set-up}

In the application the converter must be thermally insulated from the surrounding electronic detection circuitry, operating in quasi-adiabatic condition, then almost all the heat dissipated by electronics must be collected by the heat sink and extracted by the water. For this reason a test bench was built, in which all the surfaces of the heat sink, except the back side, used for measurements, were thermally insulated by a Teflon- 
polystyrene box, as illustrated in Figure 6 (a). In addition, Figure 6 (b) shows a schematic view of the measurement setup.

Three power resistors provide heat input to the heat sink. Power was regulated by a couple of TTI CPX400A power supplies. Measured parameters include inlet and outlet cooling water temperatures and the heat sink surface thermal map, obtained by two dedicated thermocouples in the connection ducts and an infrared camera (FLIR A325), respectively. In addition, three thermocouples are inserted in the thermal insulation box to monitor the resistor temperatures and prevent overheating. All the thermocouples were $k$-type. Tests were carried out by changing inlet water flow rate and electric power in the resistors. For each value of flow rate and heating power, data were collected after steady-state conditions were achieved. The steady-state conditions were assumed to be reached when the change of the maximum temperature reading was less than $0.2^{\circ} \mathrm{C}$ within $25 \mathrm{~min}$.

\subsection{Numerical model tuning}

Figure 7 (a) shows the geometry of the reference model and the water velocity field inside. We used and compared two commercial software packages: COMSOL Multiphysics and ANSYS-Fluent. The detailed flow field and heat transfer inside the heat sink were investigated by the Computational Fluid Dynamics (CFD) method, which combines the governing equations for the fluid flow with the heat convection in fluid and the heat transfer in solid

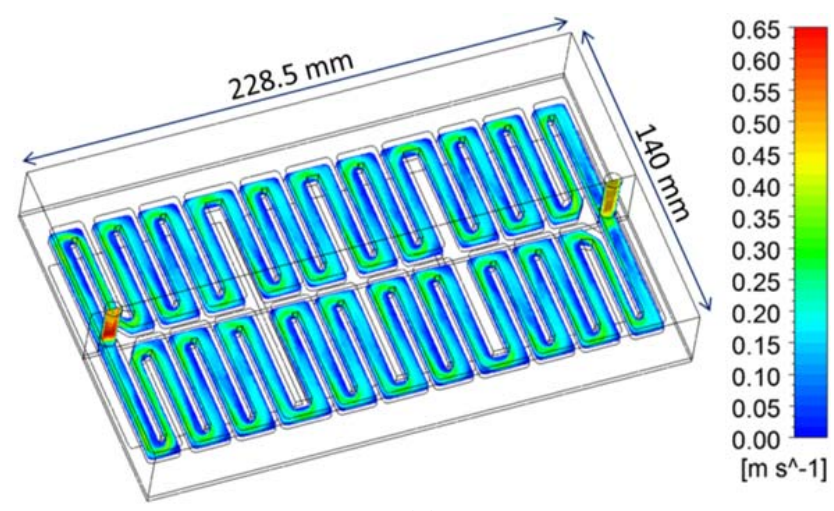

(a)

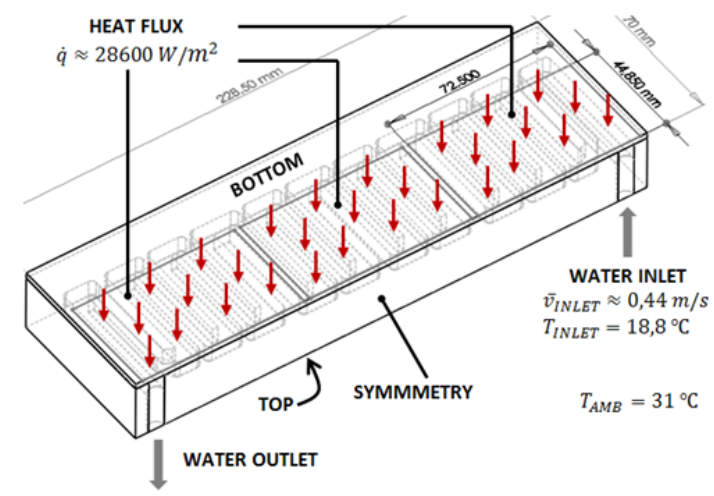

(b)

Figure 7. Geometry of the reference water heat sink (a) and FE model, with indication of boundary conditions (b). equations [18]. The relatively small inlet flow rate of the studied case (around 1 1/min) suggests water laminar flow. This preliminary hypothesis was made using the Reynolds number and was confirmed by simulation results. Figure 7 (b) shows some of the parameters set in the model (due to the symmetry, only half of the structure was modelled). The uniform heat flux on the resistors' contact surface is equivalent to their total dissipated power $(560 \mathrm{~W})$.

The lateral surfaces were set as adiabatic, while on the top surface natural horizontal air convection has been considered.

Figure 8 shows an example of simulation results (COMSOL) for a dissipated power of $560 \mathrm{~W}$ and a delivery

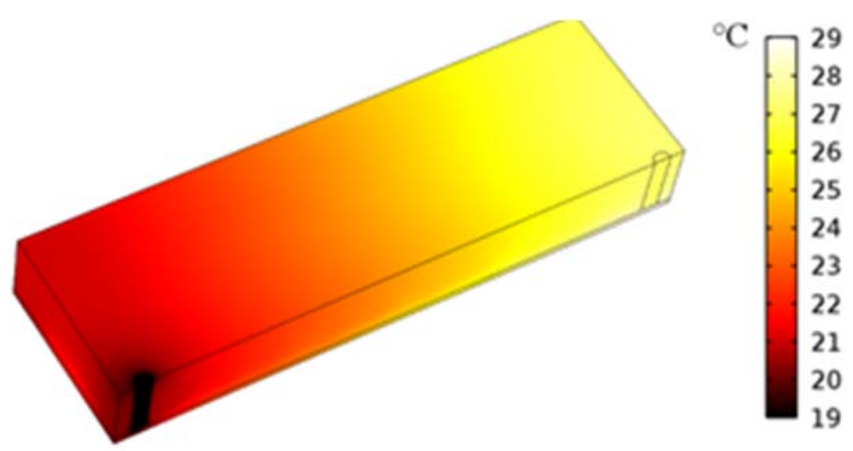

(a)

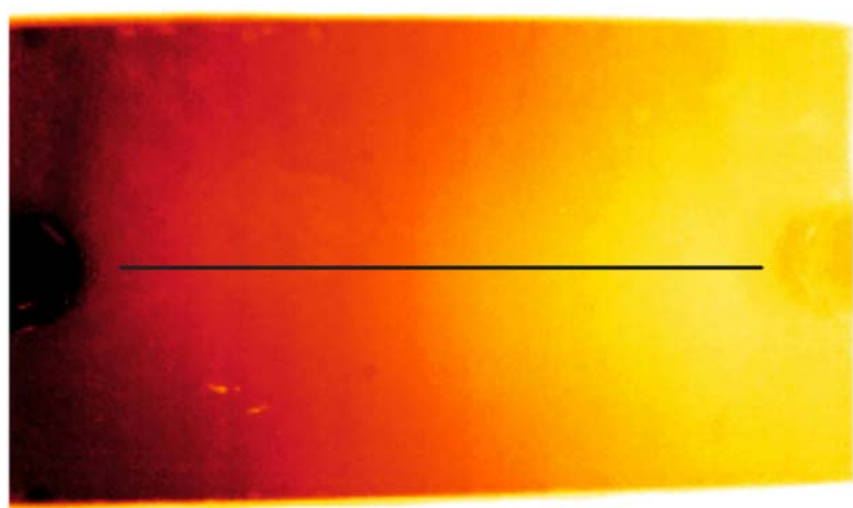

(b)

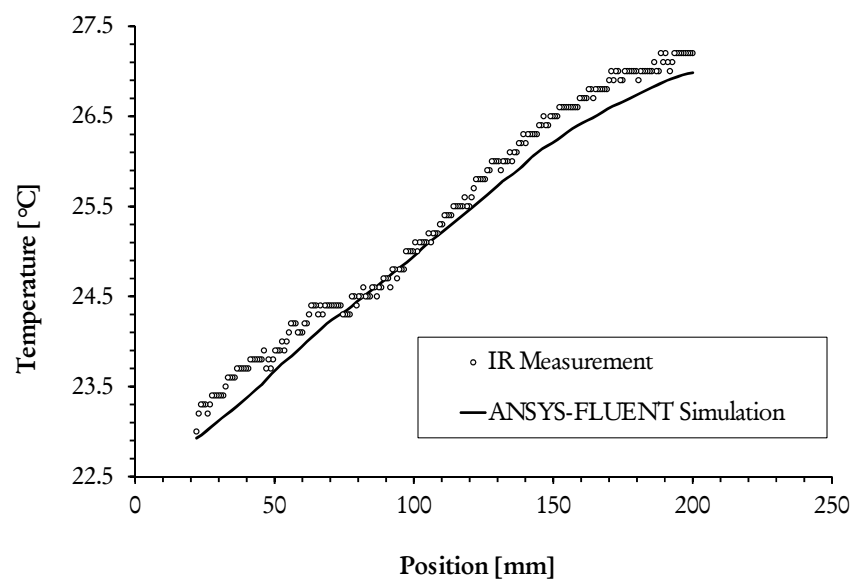

(c)

Figure 8. (a) Steady state simulated thermal map (COMSOL) for the reference heat sink (half structure) at operating conditions of Figure 7 (b); (b) IR temperature map; (c) measured and simulated (ANSYS) heat sink surface temperature along the black horizontal lines of Figure 8 (b). 


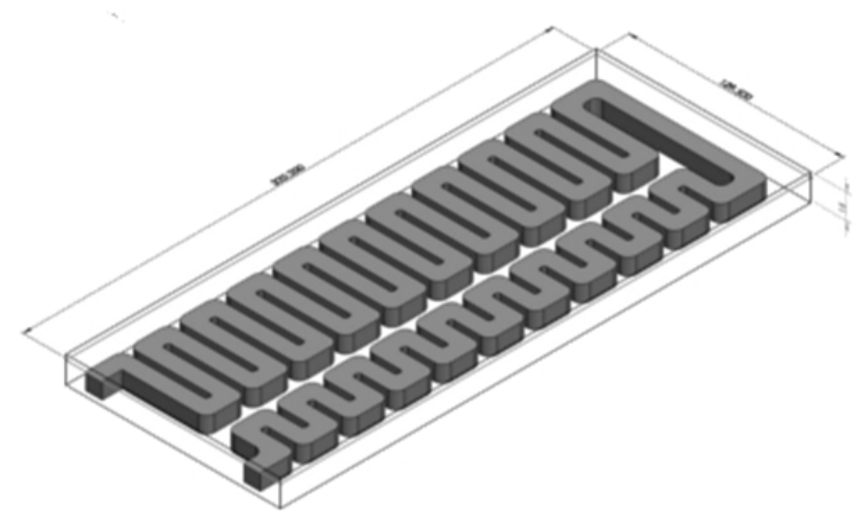

Figure 9. The 2-C heat sink.

of $1.3 \mathrm{l} / \mathrm{min}$. Maximum temperature was around $30^{\circ} \mathrm{C}$ on the heat sink and $60^{\circ} \mathrm{C}$ on the resistors.

The temperatures measured by the two thermocouples at the coolant inlet and outlet, and the temperature across the top surface estimated by infrared thermography were used for model validation. As fitting parameter the heat convection coefficient $h$ at the air-exposed boundary were set. This parameter can be estimated by a rule of thumb, but it is very hard to evaluate its actual value because it depends on many others parameters and/or operating conditions, so, to obtain good results from simulations, we tested different values to find the one that allows obtaining the best fit. Here, $b$ was set to around $7 \mathrm{~W} /\left(\mathrm{m}^{2} \mathrm{~K}\right)$, a typical value for natural air convection. By comparing the simulated thermal map of Figure 8 (a) with Figure 8 (b), which reports the corresponding IR measurement, a good agreement appears. This can be better appreciated in Figure 8 (c), which shows the comparison between temperatures along the symmetry line on the heat sink top surface. The matching is also good for water temperatures at the inlet (both $18.8^{\circ} \mathrm{C}$ ) and outlet (measurement: $24.8^{\circ} \mathrm{C}$, ANSYS simulation: $25.1^{\circ} \mathrm{C}$ ).

\section{OPTIMIZED HEAT SINK DESIGN}

The developed model was exploited to design a specific water heat sink, able to comply with constraints, which were: inlet and outlet on the same short side; thickness 15 $\mathrm{mm}$, water path diameter $5 \mathrm{~mm}$; flow rate $0.631 / \mathrm{min}$, maximum pressure drop $350 \mathrm{mbar} ; T_{\text {inlet }}=18{ }^{\circ} \mathrm{C}$; maximum $T_{\text {outlet }}=25{ }^{\circ} \mathrm{C}$. The heat generation in the converter is not

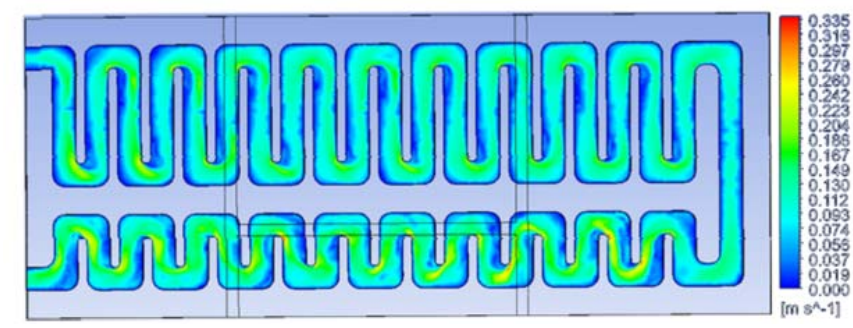

(a)

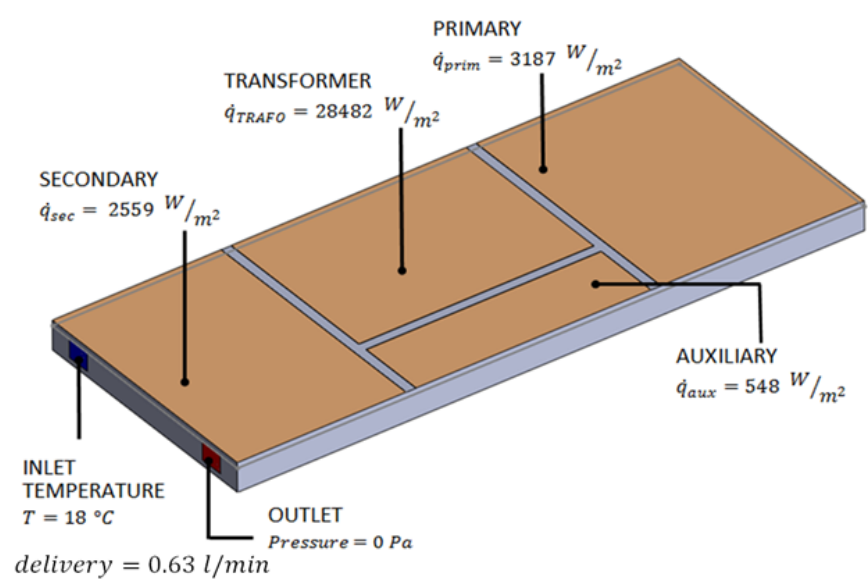

Figure 11. Boundary conditions on the heat sink surface in contact with the converter, in case of $P_{\text {out }}=1.5 \mathrm{~kW}$.

uniform, but as a first approximation, it can be divided in four main regions where heating takes place: the planar transformer region, the primary and the secondary regions and the auxiliary power supply region [6]. In order to easily evaluate the performance of different water paths we simulated the heat sink alone, by modelling the inward heat flux from the power electronics as four different uniform heat fluxes, as shown in Figure 11 for a delivered power $P_{\text {out }}=1.5 \mathrm{~kW}$.

With these boundary conditions different topologies were examined in order to enlarge as much as possible the heat exchanging surface area between solid and fluid in the region were the input heat is higher [19]. The chosen design is illustrated in Figure 10 (a).

Finally, Figure 10 (b) shows the thermal map simulated with this structure at the surface in contact with the power converter delivering $1.5 \mathrm{~kW}$.

\section{FULL CONVERTER MODELING AND CHARACTERIZATION}

The power converter was modelled by the simplified blocks method [8], [9] and the thermal behaviour of the assembly made by the converter mounted on the designed heat sink was simulated. The heat sink was fabricated by milling an aluminum plate and the aluminum cover plate brazed on it. The converter was mounted on the heat sink ensuring optimal thermal contact by a thin layer of thermal paste, and uniform pressure was guaranteed by screws.

The whole assembly was tested at different operating conditions by a test bench able to fix and measure all the

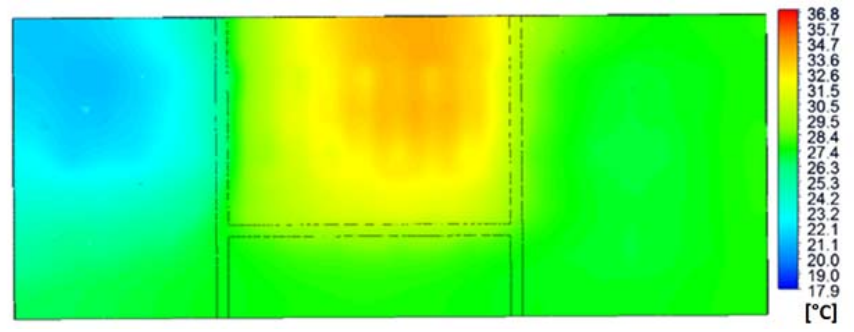

(b)

Figure 10. Water velocity field in the designed heat sink (a) and thermal map simulated at the surface in contact with the power converter operating at $P_{\text {out }}=1.5 \mathrm{~kW}(\mathrm{~b})$. 


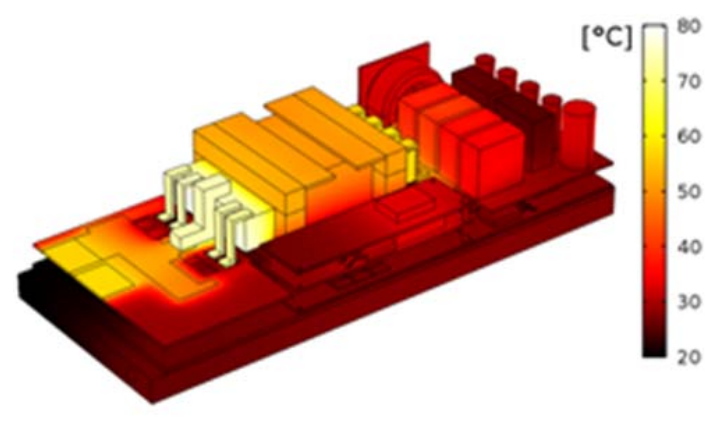

(a)

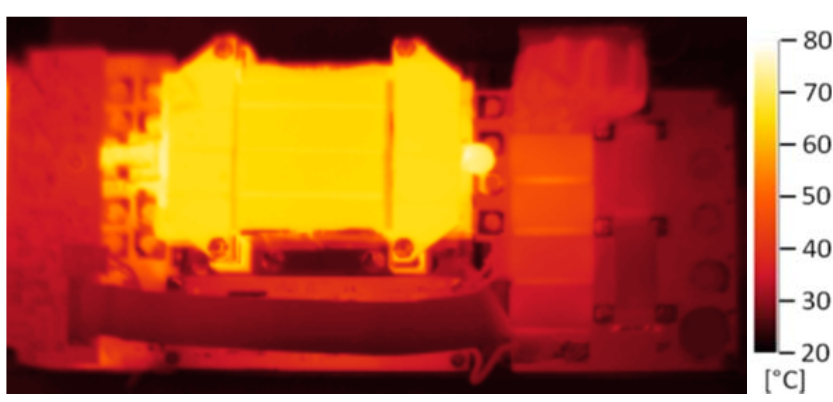

(b)

Figure 12. Thermal map of the power converter mounted on the designed heat sink at operating conditions: $P_{\text {out }}=1.2 \mathrm{~kW}, T_{\text {inlet }}=18{ }^{\circ} \mathrm{C}, T_{\text {amb }}=21^{\circ} \mathrm{C} .(\mathrm{a})$ Simulation; (b) IR measurement.

operational parameters. In particular:

a. Differential inlet/outlet water temperature by means of a thermometer based on k-type thermocouples $\left(0.1^{\circ} \mathrm{C}\right.$ of resolution) at the input and at the output of the heat sink. The minimum differential measured temperature was $1.7{ }^{\circ} \mathrm{C}$ and the maximum differential measured temperature was $2.7^{\circ} \mathrm{C}$. The mean value during the experimental activity was about $2.2{ }^{\circ} \mathrm{C}$. Both the water temperature measured during the tests and the differential inlet/outlet water temperature are in compliance with the constraints above reported: $\quad T_{\text {inlet }}=18{ }^{\circ} \mathrm{C}$; maximum $T_{\text {outlet }}=25^{\circ} \mathrm{C}$.

b. Differential inlet/outlet water pressure by means of two pressure sensors type PSE560-02 from SMC installed near the input and the output of the heat sink. The pressure is measured using an interface type PSE200-MA4C from SMC (+/- 0.5\% F.S.). The differential inlet/outlet water pressure during the experimental activity was stable at 210 mbar. This value is in compliance with the specification aforementioned. In fact, a maximum pressure drop of 350 mbar is allowed.

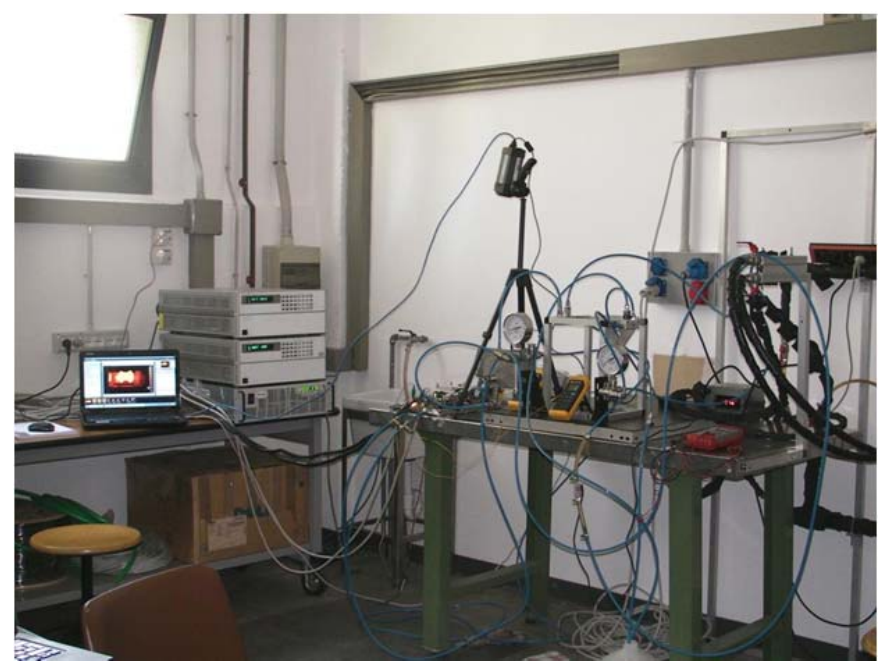

Figure 13.The experimental setup. c. Water flux by a water digital flux-meter type PF3W704-F03-BTN-M from SMC. The nominal range of the adopted sensor is $0.5-41 / \mathrm{m}(+/-3 \%$ F.S.). During the experimental activity the reading of the water flux was stable at a mean value of $0.61 / \mathrm{m}$. Also in this case, the measured value complies with constraints concerning a water flow rate $0.63 \mathrm{1} / \mathrm{min}$, as aforementioned.

d. Temperature map by a FLIR A325 infrared thermocamera. All the reflecting surfaces were painted black, in order to obtain an almost homogeneous emission coefficient.

e. Temperature of the most heating components by means of $k$-type thermocouples and PC-driven switching unit.

Figure 12 shows, as an example, the comparison between simulation and measurement in the case of the converter delivering $P_{\text {out }}=1.2 \mathrm{~kW}$.

In Figure 13 the experimental setup has been depicted. The positions of the thermocouples are depicted in Figure 14 whereas in Table 1 the function of every thermocouple is finally described.

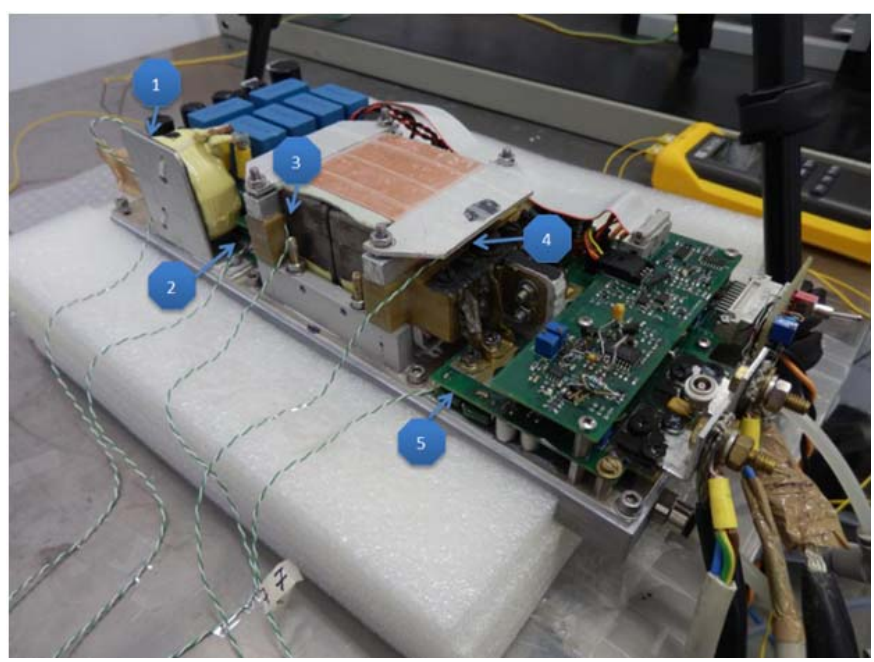

Figure 14. Thermocouples position inside the MC. 
Table 1. Thermocouples position.

\begin{tabular}{cl}
\hline Thermocouple & Position \\
\hline 1 & Toroidal inductor \\
2 & MOSFET drain flange at primary \\
3 & Planar transformer core (inner point) \\
4 & Planar transformer windings (inner point) \\
5 & ISOTOP diode flange for heat-sink at secondary \\
6 & Ambient (not shown in Figure 14) \\
\hline
\end{tabular}

\section{DISCUSSION}

Complex systems operating inside the LHC must comply with very stringent RAMS requirements. One of the key issues is the thermal behaviour of electronic converters in power supplies.

An accurate thermal modelling, accounting for conduction, air convection and fluid-dynamic heat transport, drives to the knowledge of the most critical components and conditions in the system, allowing the design of an optimized water heat-sink.

Moreover, we asserted the importance of performing preventive diagnostics. This is true even at the design stage. At this time the identification of the most appropriate positions for temperature sensors able to detect component degradation at the early stage is mandatory. In this way, with the support of the developed thermal model, it is possible to identify and localize thermal and/or thermomechanical degradation modes, and it is possible to take proper corrective actions and even to substitute power modules which show component degradation, when maintenance interruptions are scheduled.

It is important to highlight that predictive diagnostics can also put out design errors or weaknesses of the design. For example, the planar transformer proved to be the weakest point only after the thermo-graphic analysis and simulation of the complete main converter. In fact, in the design phase with electronic simulation tools (such as SPICE) it is not always possible to put in full light the aspects of thermal dissipation. Finally, it is important to highlight that predictive diagnostics can therefore lead to design reviews with significant savings in the prototyping phase.

\section{CONCLUSIONS}

After a brief description of an isolated DC-DC MC able to supply an intermediate "medium" voltage on a distribution bus for ATLAS (LAr), a coupled thermo-fluiddynamic 3D model of a water heat sink for power electronic converters has been developed and tuned by thermal characterization of a known prototype. The model was used for designing a suitable solution for a specific complex DC-DC converter for application in LHC future experiments, with very stringent thermal constraints. The heat sink was fabricated and thermal measurements performed on the converter mounted on it show a good agreement with thermo-fluid-dynamic simulations of the whole assembly. The proposed cold plate can be utilized with the MC in order to obtain the wanted delivered power.

Considerations about dependability of the proposed MC have been presented. In particular, the reliability of the adopted solution has been discussed. Finally, both diagnostic aspects and maintenance strategies in compliance with the experimental activity have been discussed.

\section{ACKNOWLEDGEMENT}

The authors would like to thank the other members of the APOLLO collaboration, founded by Italian Istituto Nazionale di Fisica Nucleare (INFN), for their fruitful support [20].

\section{REFERENCES}

[1] http://home.web.cern.ch.

[2] G. Aad et al., The ATLAS experiment at the CERN LHC, Journ. of Instrumentation 3 (2008) S08003.

[3] J. Bohm, J. Stastny, V. Vacek, Cooling performance test of the SCT LV\&HV power supply rack, ATL-INDET-PUB2006-004, Nov. 2005.

[4] P. Tenti, G. Spiazzi, S. Buso, M. Riva, P. Maranesi, F. Belloni, P. Cova, R. Menozzi, N. Delmonte, M. Bernardoni, F. Iannuzzo, G. Busatto, A. Porzio, F. Velardi, A. Lanza, M. Citterio, C. Meroni, Power supply distribution system for calorimeters at the LHC beyond the nominal luminosity, Journ. of Instrumentation 6 (2011) P06006.

[5] M. Lazzaroni, L. Cristaldi, L. Peretto, P. Rinaldi and M. Catelani, Reliability engineering: basic concepts and applications in ICT, Springer-Verlag, Berlin Heidelberg, 2011, ISBN 978-3-642-20982-6, e-ISBN 978-3-642-20983-3.

[6] ISO 9000:2005, Quality management systems - Fundamentals and vocabulary.

[7] M. Alderighi, M. Citterio, M. Riva, S. Latorre, A. Costabeber, A. Paccagnella, F. Sichirollo, G. Spiazzi, M. Stellini, P. Tenti, P. Cova, N. Delmonte, A. Lanza, M. Bernardoni, R. Menozzi, S. Baccaro, F. Iannuzzo, A. Sanseverino, G. Busatto, V. De Luca, F. Velardi, Power converters for future LHC experiments, Journ. of Instrumentation 7 (2012) C06012.

[8] P. Cova, N. Delmonte, Thermal modeling and design of power converters with tight thermal constraints, Microelectronics Reliability 52 (2012) pp. 2391-2396.

[9] P. Cova, N. Delmonte, R. Menozzi, Thermal characterization and modeling of power hybrid converters, Microelectronics Reliability, 46 (2006) pp. 1760-1765.

[10] S. Baccaro, G. Busatto, M. Citterio, P. Cova, N. Delmonte, F. Iannuzzo, A. Lanza, M. Riva, A. Sanseverino, G. Spiazzi, Reliability oriented design of power supplies for high energy physics applications, Microelectronics Reliability 52 (2012) pp. $2465-2470$.

[11] http://mag-inc.com/products/powder-cores/kool-mu/learnmore-kool-mu.

[12] L. Cristaldi, M. Faifer, M. Rossi, S. Toscani, M. Lazzaroni, "Condition based maintenance through electrical signature analysis: a case study", I2MTC International Instrumentation and Measurement Technology Conference, May 3-6, 2010, Austin, Texas, USA, pp. 1169 - 1174.

[13] L. Cristaldi, M. Faifer, M. Lazzaroni, S. Toscani, An inverter-fed induction motor diagnostic tool based on timedomain current analysis, IEEE Trans. on Instrumentation 
and Measurement 58 (2009) pp. 1454-1461.

[14] L. Cristaldi, M. Lazzaroni, A. Monti, F. Ponci, F.E. Zocchi, "A genetic algorithm for fault identification in electrical drives: A comparison with neuro-fuzzy computation", IMTC Instrumentation and Measurement Technology Conference, May 18-20, 2004, Como, Italy, pp. 1454-1459.

[15] L. Cristaldi, M. Lazzaroni, A. Monti, F. Ponci, A neurofuzzy application for AC motor drives monitoring system, IEEE Trans. on Instrumentation and Measurement 53 (2004) pp. 1020-1027.

[16] A. Azzini, L. Cristaldi, M. Lazzaroni, A. Monti, F. Ponci, A.G.B. Tettamanzi, "Incipient fault diagnosis in electrical drives by tuned neural networks", IMTC Instrumentation and Measurement Technology Conference, April 24-27, 2006, Sorrento, Italy, pp. 1284-1289.
[17] L. Cristaldi, M. Faifer, M. Lazzaroni, S. Toscani, "A VI based tool for inverter fed induction motor diagnostic", IMTC Instrumentation and Measurement Technology Conference, May 12-15, 2008, Victoria, Canada, pp. 15601565.

[18] J.H. Ferziger and M. Peric, Computational methods for fluid dynamics, Springer, 2002, ISBN-10: 3540420746, ISBN-13: 978-3540420743.

[19] P. Cova, N. Delmonte, F. Giuliani, M. Citterio, S. Latorre, M. Lazzaroni, A. Lanza, Thermal optimization of water heat sink for power converters with tight thermal constraints, Microelectronics Reliability 53 (2013) pp. 17601765.

[20] http://www2.pv.infn.it/ servel/apollo/index.html. 